\title{
INTENSE UV ENRICHED PHOTO DETECTION BYHIGHER ENERGY EDGE ATTUNED COATING ON CSI DETECTOR
}

\author{
Bablu K. Ghosh' ${ }^{1}$ Ismail Saad ${ }^{2}$, Khairul Anuar Mohamad ${ }^{3}$, Saiful S. Mohd Zainal ${ }^{4}$ \\ ${ }^{1,2,3}$ Senior lecturer, ${ }^{4}$ Research Assistant, EEE program, SEIT, University Malaysia, Sabah, Malaysia, \\ ghoshbab@ums.edu.my, ismail_s@ums.edu.my,Khairul@ums.edu.my, saifulsapri90@gmail.com
}

\begin{abstract}
Solar UV detector industrial applications and monitoring is potential approach for technology based industrial development and ecosystem management aspects. Respect to visible spectrum both shorter and longer line width are not so promising for solar energy detecting/ harvesting by using Si technology. For lower energy edge of UV band absorption process, utilization of UV compatible higher energy edge reaping supportive thickness of additional $\mathrm{Si}_{3} \mathrm{~N}_{4}$ layer on $\mathrm{SiO}_{2}$ coating layer for crystalline c-Si detector is found promising. As compared to single $\mathrm{SiO}_{2}$ coating layer or bared c-Si cell, applications of $\mathrm{SiO}_{2}+\mathrm{Si}_{3} \mathrm{~N}_{4}$ double coating layer enhancement of the detector current or responsivity is specifically observed. Compare to lower energy edge of solar spectrum, UV (A-B) band enhanced energy conversion slant is found attractive. In this article, using $\leq 60 \mathrm{~nm} \mathrm{SiO}{ }_{2}+\mathrm{Si}_{3} \mathrm{~N}_{4}$ harmonized coating layers on $P^{+} \mathrm{N}$, $N^{+} P$ and $P^{+} I N$ Si based detector, very intense UV band response is realized. It appears that tiny i-layer with minimum n-doping in $P^{+} i N$ structure as compared to the $P^{+} N$ detector, increases the conversion efficiency. Compared to $P^{+} N$ detector $N^{+} P$ detector responsivity or conversion efficiency is found to be enhanced explicitly.
\end{abstract}

Keywords: UV detector, $\mathrm{Si}_{3} \mathrm{~N}_{4}$ coating, eco-system, UV enhancement, Solar energy harvesting $* * *$

\section{INTRODUCTION}

High performance ultraviolet Photo detector (PD) has immense applications in the field of industry, medical as well as integration for future imaging sensor purposes [1-4]. In the tropical region due to higher UV irradiance, it may affect severely on our eco-system [5-7]. In the leaves of tropical trees, the ambient $\mathrm{UV}(\mathrm{A}-\mathrm{B})$ radiation contribute to the reversible decline in potential PSII efficiency observed upon exposure. UV (A-B) radiation is known to have a wide range of harmful effect as reduced productivity of both freshwater and marine organism and eco-system [5-7]. Though $0.8 \%$ of solar radiation as UV (A-B) reaches on the earth but it causes $50 \%$ photochemical actions in the earth environment [5-7]. So enhance UV band detection for ecosystem management and monitoring is also important for sustainability. Clean energy harvesting is also very promising issue for future development. For a particular material based solar detector band gap is fixed, so whenever its responsivity will be increased obviously its efficiency must be increased. So, different approaches for efficient solar band energy harvesting using $\mathrm{Si}$ technology are highly potential and it is well addressed [8]. Both $\mathrm{SiO}_{2}$ and $\mathrm{Si}_{3} \mathrm{~N}_{4}$ are equally transparent even for high energy edge UV band of solar spectrum. $\mathrm{SiO}_{2}$ is highly technically established materials as a passivation layer for Si based MOS technology and it may also be used for integration of PD technology [4]. $\mathrm{Si}_{3} \mathrm{~N}_{4}$ is also potential coating materials against degradation of detecting device even in high radiation environment and temperature [9].Variation of photo detector performance on body doping is also studied elsewhere [10]. To achieve higher UV band sensitivity; quantum efficiency or gain due to high energy photon in the front window of the detector is required to address in well manner. In this paper, enhancement of solar UVA and UVB band sensitivity using $\mathrm{SiO}_{2}+\mathrm{Si}_{3} \mathrm{~N}_{4}$ coating layer on crystalline $\mathrm{Si}$ (c-Si)based detector approach is materialized for future ecosystem management [5-7]and industrial aspects [1-4].

\section{EXPERIMENTAL}

$\mathrm{N}$-tpe c-Si wafer based $\mathrm{P}^{+} \mathrm{N}, \mathrm{N}^{+} \mathrm{P}$ and $\mathrm{P}^{+} \mathrm{iN}$ photo detectors are fabricated based on TCAD software. Using different thickness $\mathrm{SiO}_{2} / \mathrm{SiO}_{2}+\mathrm{Si}_{3} \mathrm{~N}_{4}$ coating (window) layers are designed for simulation and analysis of whole solar spectrum response. Besides that without coating layer or with single different materials coating layer effect is made for comparison. Different concentration body doping and active layer doping profile is also done in the simulation process. For the efficiently conversion aspect of UBA and UVB band photons to cathode or output current, suitable thickness $\mathrm{SiO}_{2}+\mathrm{Si}_{3} \mathrm{~N}_{4}$ coatings is made in the process. Designed window area- $1 \mathrm{~mm}^{2}$, irradiation $-1 \mathrm{~W} / \mathrm{cm}^{2}$ and responsivity unit- $\mathrm{A} / \mathrm{W}$ are considered. 


\section{RESULTS AND DISCUSSION}

Usually those photons are absorbed in the active region or close to the active region of a detector junction and before recommbine as electron-hole (e-h) pair may acts as photocurrent at the load.

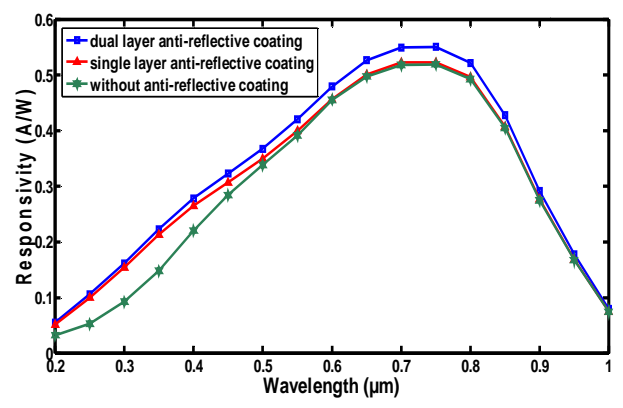

Fig-1: Responsivity of Si detector with different coarings

In figure-1 using $\mathrm{SiO}_{2}+\mathrm{Si}_{3} \mathrm{~N}_{4}, \mathrm{SiO}_{2}$ and without coating the differences of photoresponse are clearly observed. So UV coated layer on Si prefer to enhance the responsivity. It may due to the dangling bonding between $\mathrm{Si}$ and $\mathrm{SiO}_{2}$ at the interface favors to absorb UV(A-B) bands and enhances the conversion efficiency.

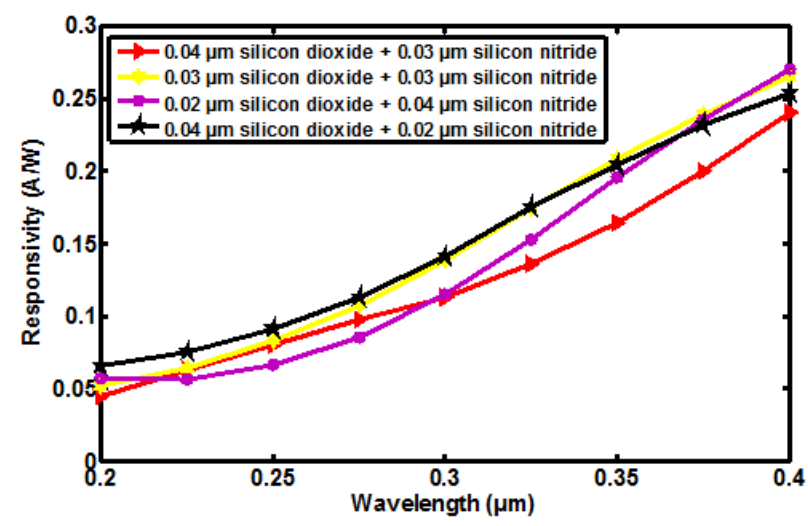

Fig-2: Simple PN photodiode with different combiniational $\mathrm{SiO}_{2}+\mathrm{Si}_{3} \mathrm{~N}_{4}$ thickness coatings

Figure -2 shows the simulation result of $\mathrm{Si}$ detector with different combiniational $\mathrm{SiO}_{2}+\mathrm{Si}_{3} \mathrm{~N}_{4}$ thickness coatings. The thickness and type of the anti-reflection coating (ARC) is chosen such a way that it can minimize the interference effects by the wave reflected from the ARC top surface to be out of phase with the wave reflected from the $\mathrm{Si}$ semiconductor surfaces. These out-of-phase reflected waves destructively interfere with one another, resulting in zero net reflected energy. Thus the thickness and type of materials to be used for the coating are required to analyze in order to obtain the best coating thickness and materials for higher responsivity. Compare to linearity and performance aspect more $\mathrm{SiO}_{2}$ thickness is prone better detection of high energy edge of UV band while more $\mathrm{Si}_{3} \mathrm{~N}_{4}$ thickness found very promising for $\mathrm{UV}(\mathrm{A}-\mathrm{B})$ band enhancement of detection.

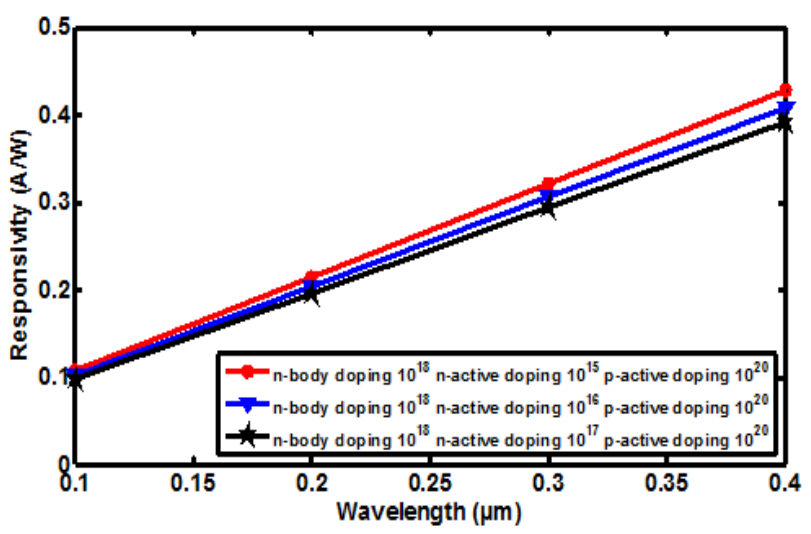

Fig-3: $\mathrm{P}^{+} \mathrm{N}$ photodiode with different doping in $\mathrm{n}$-active layer

High-refractive-index $(n=2.05)$ and permissible band gap $(\sim 5 \mathrm{eV}), \mathrm{Si}_{3} \mathrm{~N}_{4}$ materials bounded by air $(\mathrm{n}=1)$ and $\mathrm{SiO}_{2}$ $(\mathrm{n}=1.57)$. The $\mathrm{Si}$ refractive index $(\mathrm{RI})$ is quite large as compared to air leads to high optical losses due to reflection. Anti- reflector with minimized reflection and maximize the photo-current generation is desirable as photon management aspects. Compared to air $\left(\mathrm{RI}, \mathrm{n}_{\mathrm{o}}=1\right)$ and $\mathrm{cSi}\left(\mathrm{RI}, \mathrm{n}_{2}=\sim 3.4\right)$ the intermediate layer RI should be $n_{1}=\sqrt{ }\left(n_{0} n_{2}\right)=1.84$ as geometric mean but $\mathrm{SiO}_{2}, \mathrm{RI}=1.57$. So, only $\mathrm{SiO}_{2}$ is not suitable coating for optimization against reflection. $\mathrm{Si}_{3} \mathrm{~N}_{4}$ hasRI $=2.05$, so $\mathrm{Si}_{3} \mathrm{~N}_{4}$ and $\mathrm{SiO}_{2}$ refractive index geometric mean, $\mathrm{n}_{1}=\sqrt{ }(1.57 * 2.05)=\sim 1.8$. It seems to be harmonization with the air to $\mathrm{cSi}$ interface thus enhancing the conversion efficiency from UV to visible spectra and linearity also found in UV range.

The linearity of responsivity, its sensitivity or photo-current generation process truely depends on the junction depth, photon absorption coefficient or how depth the photon are absorbing and the quality of the crystalline detector. If absorption is occurred at the nearby depletion width and less defect crystal; it may enhances resistivity hence the leakage provision is also reduced. Applying the single sided detector with $\mathrm{P}^{+} \mathrm{N}$ junction and variation of $\mathrm{N}$-active layer doping concentration the effect on responsivity is analyzed in our study. Figure- 3 shows the impact of $\mathrm{P}^{+} \mathrm{N}$ junction with different doping concentration of $n$. 
Optical losses mostly effect the power from a detector by lowering the short-circuit current. It consists of light which could have generated an electron-hole pair, but does not, because the light is reflected from the front surface, or because it is not absorbed in the solar cell. For the most common semiconductor detector, the entire visible spectrum (350 - 780 $\mathrm{nm})$ has enough energy to create electron-hole pairs and therefore all visible light would ideally be absorbed. But enhancement of UV range detection is realised by using the combinational coating while variation of $\mathrm{n}$ active layer doping is a factor. $\mathrm{P}^{+} \mathrm{N}$ detector is achieved higher responsivity and linearity as compared to $\mathrm{PN}$ detector as found in figure 2 and 1 respectively. So, comparatively lower band gap $\mathrm{Si}_{3} \mathrm{~N}_{4}$ additional coating band gap $(\sim 5 \mathrm{eV})$ match with the $250-300$ $\mathrm{nm}$ edge of solar spectrum is found very effective to increase the responsivity or photo-current of c-Si photo detector. Due to application of proper coating with adjustable depth of depletion width obviously the detection responsivity is increased as published elsewhere [10].

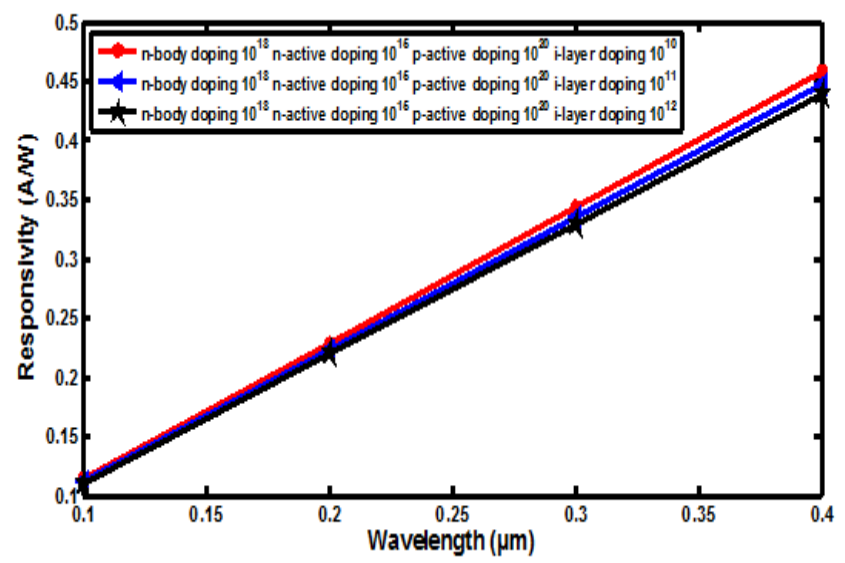

Fig-4: $\mathrm{P}^{+}{ }^{+} \mathrm{N}$ photodiode with different $\mathrm{n}$-intrinsic layer doping

The above result shows that the increment of depletion width by lowering $\mathrm{N}$ layer doping enhances the UV responsivity with linearity. For the high energy edge of solar spectrum, effective absorption with lowest depletion depth from the surface is appreciable. So low doping in the active n-region and very high doping in the surface $P$ region is found attractive to increase the responsivity. In this process, insertion of additional intrinsic type layer effect between active $\mathrm{p}^{+}$and $\mathrm{n}$ layer is investigated. To find the effect of depletion width, further an intrinsic layer with different $\mathrm{n}$ doping effect is investigated. Depletion layer variation due to doping/ intrinsic layer can also varying the junction capacitance and even the speed of the detector due to variation of bandwidth is also varied as mentioned elsewhere [11].
Figure-4 shows the effect of inserted intrinic layer and its doping variation.Detector sensitivity, responsivity and enhancement for UV detection are realized in the analysis. It shows that $\mathrm{P}^{+} \mathrm{iN}$ further enhances the detector responsivity compared to the $\mathrm{P}^{+} \mathrm{N}$ detector. It may happen due to reduce the capacitance at the junction, reduce the transient effect thus the device must be achieved higher conversion efficiency or responsivity for 0.1 to $0.4 \mu \mathrm{m}$ line edge getting bit higher.

Usually $\mathrm{P}^{+} \mathrm{N}$ and $\mathrm{N}^{+} \mathrm{P}$ detector have different aspects of photo response, it is also investigated in the work. Figure- 4 shows the optimised $\mathrm{SiO}_{2}+\mathrm{Si}_{3} \mathrm{~N}_{4}$ harmonized coated $\mathrm{P}^{+} \mathrm{N}$ and $\mathrm{N}^{+} \mathrm{P} \mathrm{Si}$ detector. It appears that $\mathrm{P}^{+} \mathrm{N}$ detector responsivity at the longer wavelength range is low even it maximize at $\sim 700 \mathrm{~nm}$ whereas $\mathrm{N}^{+} \mathrm{P}$ detector is promising for longer wavelength. The quantum efficiency or responsivity throughout the UV band is found similar in both cases but at the middle of the spectrum $\mathrm{P}^{+} \mathrm{N}$ detector is found higher responsivity as compared with the $\mathrm{N}^{+} \mathrm{P}$ detector. At the lower energy band photon absorption at the depletion edge appears to be supported by hole as minority carrier usually possesses higher diffusion length thus increases it. In addition, lower energy edge large numbers of photon with minimum energy appears to absorb effectively at the junction of $\mathrm{N}^{+} \mathrm{P}$ detector and thus increases the responsivity. Overall conversion efficiency or responsivity is precisely observed higher as it published by other researches elsewhere [12-13].

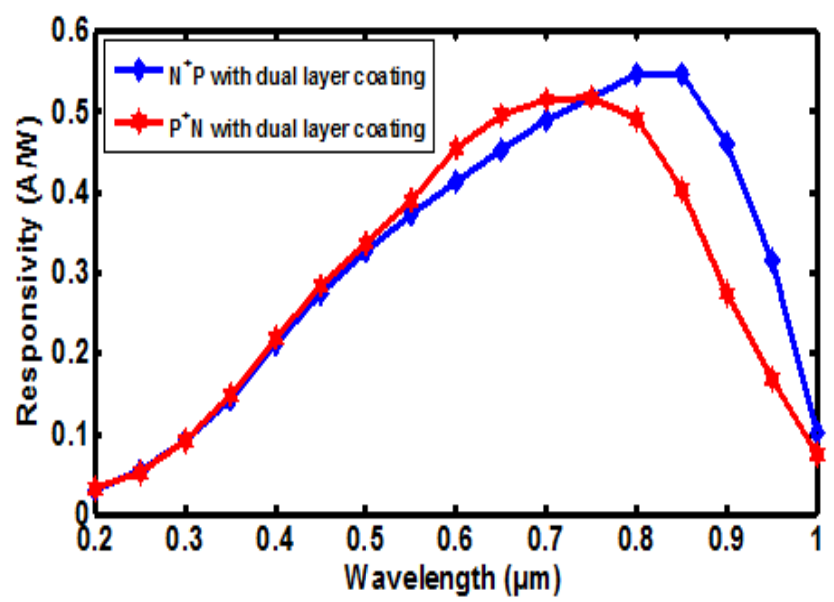

Fig-5: $\mathrm{P}^{+} \mathrm{N}$ and $\mathrm{N}^{+} \mathrm{P}$ photodiode with UV harmonized $\mathrm{SiO}_{2}+\mathrm{Si}_{3} \mathrm{~N}_{4}$ thickness coatings

So the above analysis justify that the enhancement of UV(AB) for 0.28 to $0.4 \mu \mathrm{m}$ line edge of the solar spectrum is precisely observed. So, suitable technique to absorb those photons effectively in the proper matched depletion region could enhance the detector quantum efficiency or responsivity. 


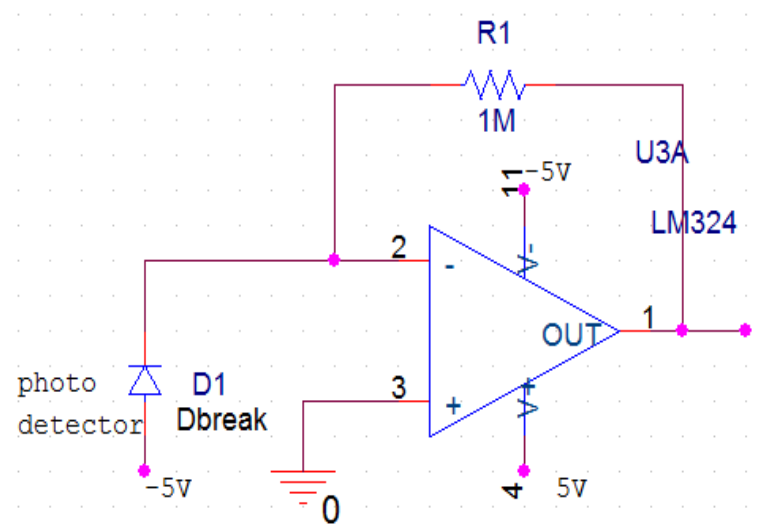

Fig-6: Current to voltage convertor using the detector output current as response input for the amplifier

The result of the amplifier designed as current to voltage convertor as shown in figure- 6 . The simulated data is also shown in below table-1

Table -1: Response signal from detector

\begin{tabular}{|c|c|c|}
\hline $\begin{array}{c}\text { Wavelength } \\
(\mathrm{nm})\end{array}$ & $\begin{array}{c}\text { Input current } \\
(\mu \mathrm{A})\end{array}$ & $\begin{array}{c}\text { Operational } \\
\text { amplifier output } \\
\text { voltage }(\mathrm{mV})\end{array}$ \\
\hline 280 & 0.014 & 90 \\
\hline 300 & 0.018 & 120 \\
\hline 320 & 0.022 & 150 \\
\hline 340 & 0.026 & 180 \\
\hline 360 & 0.030 & 210 \\
\hline 380 & 0.034 & 240 \\
\hline 400 & 0.038 & 270 \\
\hline
\end{tabular}

From the above table data, it appears that even tiny input current for UV (A-B) bands promote reasonable signal at the output of the amplifier signifies the suitableness of Si UV(AB) detector designed by the promising coating materials with crucial thickness selection.

\section{CONCLUSIONS}

Harmonized coating layers effect on enhancement of UV (A$\mathrm{B})$ band detection using $\mathrm{C}-\mathrm{Si}$ is investigated throughout the work. The $\mathrm{SiO}_{2}$ and $\mathrm{Si}_{3} \mathrm{~N}_{4}$ combinational coating on c-Si is found most promising for the thickness ranges around $\lambda / 4$ ( $\leq 60 \mathrm{~nm}$ ) for responsivity at higher energy edge of UV(A-B) band. The conversion efficiency and linearity is found to increase precisely for $\mathrm{P}^{+} \mathrm{N}$ and $\mathrm{P}^{+} i \mathrm{~N}$ detectors. The $\mathrm{N}^{+} \mathrm{P}$ detector is found higher responsivity /conversion efficiency as compared to $\mathrm{P}^{+} \mathrm{N}$. It may due to better minority carrier (hole) life time and excess $\mathrm{n}$ carrier at the surface passivation or ohmic contact effect. So it's realized that using proper coating layers thickness on c-Si, UV absorption inside the active layer can be controlled eventually the conversion efficiency can also be optimized for a given electrostatic condition at the junction of the detector.

\section{ACKNOWLEDGEMENTS}

I would like to thanks the UMS authority to use my FRGS grant FRG0307-TK-1/2012. I would like to thanks my student for supporting me in this work.

\section{REFERENCES}

[1]E. Monroy, F. Omnès and F. Calle, "Wide-bandgap semiconductor ultraviolet photo-detectors", Semiconductor Science and Technology, vol. 18, no. 4, pp. 33-51, Apr. 2003. [2] A. Karczemska and A.Sokolowska, "Materials for DNA sequencing chip", Abstract book of 3rd International Conference on Novel Applications of Wide Bandgap Layers, pp. 176, June 2001.

[3] G. Knight, "Monitoring of ultraviolet light sources for water disinfection", Proc. 39th IEEE Industry Applications Conference, pp. 1016-1018, Oct. 2004. 3363, Oct. 2010.

[4]. Eujune Lee Et, Al., IEEE Electron Device Letters, Vol. 30, No. 5, May 2009

[5] R. Bhattacharya et al., International Journal of Engineering Science and Technology (IJEST), Vol. 4 No.08 August 2012,P 3824-3832

[6] M. M. Caldwell et, al., The Environmental Effects Assessment Panel Report for 2006, P 65-94

[7] D.-P. Haderet.al Photochem. Photobiol. Sci., 2007, 6, $\mathrm{P} 267-285$

[8] Tatsuo Saga, NPG Asia Materials (2010) 2, 96-102

[9] Sinje K-C et. al., 26th EU PVSEC - European Photovoltaic Solar Energy Conference \& Exhibition, 05-09 Sept., 2011[10] OSI Optoelectronics, www.osioptoelectronics.com, application notes P-74, and UTD sensor Inc., www. utd.com, P-7

[11] Bablu K Ghoshet. al., Computer Applications and Industrial Electronics (ISCAIE), 2012 IEEE; Dec., 3-4@2012 IEEE, P-245-249

[12] A. Pauchard , P.-A. Besse, R.S. Popovic, Sensors and Actuators 76,1999 P-172

[13] T. Yu, J. van de Lagemaat, MRS Bulletin,V. 36, June 2011, P -424 


\section{BIOGRAPHIES}

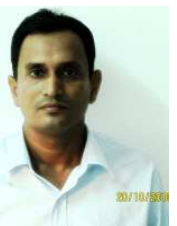

Dr. Bablu K. Ghosh received his doctor of engineering degree from Fukui University, Japan in 2004 in system design engineering. Before that he did his undergraduate and master's degree in applied Physics and Electronic Engineering from RU, Bangladesh.Currently he is working on Photo-detector and SPV system. Before Joining in UMS he was engaged in electronic and EM engineering fields.

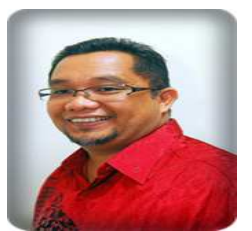

Dr. Ismail Saad received his BEng (Hons) in Electronics / computer Engineering and MSc from University of Southampton UK specializing in Microelectronics System Design in 2001. In 2009, he received his PhD from University Technology Malaysia (UTM) specializing in Micro \&Nano electronics Device and Materials.

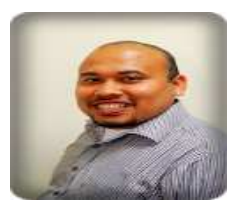

Dr. Khairul Anuar received his BEng (Hons) in Electronics Engineering and MSc from University of Newcastle upon Tyne, UK. In 2011, he received his PhD from Muroran Institute of Technology, Hokkaido, specializing in Organics Nano electronics Device and Materials

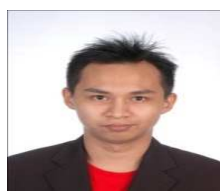

Mr. Saiful SM Zainal is going to receive his BEng (Hons) in Electrical and Electronics Engineering from University Malaysia Sabah in 2013.He is now working as research assistant under Dr. Bablu K. Ghosh`s Project and doing research work on nano-coating impact on solar energy harvesting using cSibase 